Portland State University

PDXScholar

1956

\title{
A Manual for Objective TAT Scoring
}

Richard H. Dana

Portland State University

Follow this and additional works at: https://pdxscholar.library.pdx.edu/rri_facpubs

Part of the Other Psychiatry and Psychology Commons Let us know how access to this document benefits you.

\section{Citation Details}

Dana, Richard H., "A Manual for Objective TAT Scoring" (1956). Regional Research Institute for Human Services. 34.

https://pdxscholar.library.pdx.edu/rri_facpubs/34

This Working Paper is brought to you for free and open access. It has been accepted for inclusion in Regional Research Institute for Human Services by an authorized administrator of PDXScholar. Please contact us if we can make this document more accessible: pdxscholar@pdx.edu. 


\title{
A Manual for Objective TAT Scoring
}

\author{
Richard $\mathrm{H}$, Dana \\ St. Lovis State Hospital
}

\section{lenponb mss}

rasb.

The research in this manual was carried out, in connection with an investigation supported in part by a research grant from The National Institute of Nental Health, of the National Institutes of Health, Public Health Service,

1956 
Table of Contents

Preface

Introduction..........................

Rationale............................... I

Scoring Categories....................... I

1. Perceptual Organization................. I

Description...................... I

Scoring Directions.................. 2

2. Perceptual Range..................... 3

Description..................... 3

Scoring Directions................ 3

3. Perceptual Personalization.............. 4

Description....................... 4

Scoring Directions................. 4

Card Selection........................ 5

Subjects.............................. 7

Reliability........................... 10

Validity ............................. 15

$T-S c o r e s \ldots \ldots \ldots \ldots \ldots \ldots \ldots \ldots \ldots \ldots \ldots \ldots \ldots \ldots \ldots \ldots \ldots \ldots .24$

Discussion............................. 26

References............................. 32

Appendix A.............................. 32

Score sheet, male

Score sheet, female 
List of Tables.

1. Product-moment Correlations of PO Scores for Eaoh Card with PO Score

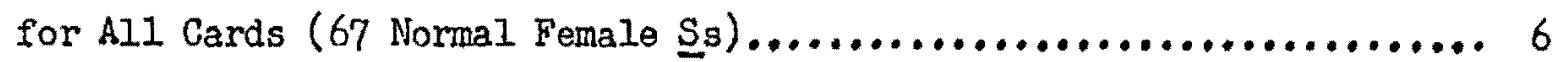

2. Product-moment Intercorrelations Between PO Scores on Five Cards $\left(67\right.$ Nomal Female $\left.s_{s}\right) \ldots \ldots \ldots \ldots \ldots \ldots \ldots \ldots \ldots \ldots \ldots \ldots \ldots \ldots \ldots \ldots \ldots \ldots \ldots$

3. Froduct-moment Intercorrelations of Categories PO, PR, PP for Three

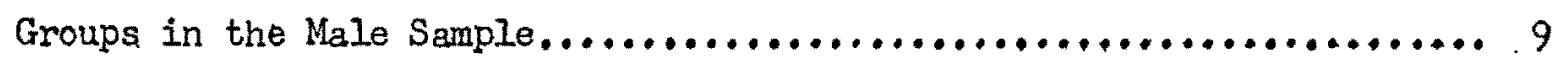

4. Scoring Category Reliability (per cent of agreement) for Male Validation, Male Cross-Validation (c), and Female Validation Samples... Il 5. FO Item Reliability (per cent of agreement) for Male Validation, Male Cross-validation (c), and Female Validation Samples............... 12

6. PR Item Reliability (per cent of agreement) for Male Validation, Male Cross-validation (c), and Female Validation Samples............... 13 7. PP Category Reliability (per cent of agreement) by Sexes and Diagnostic.

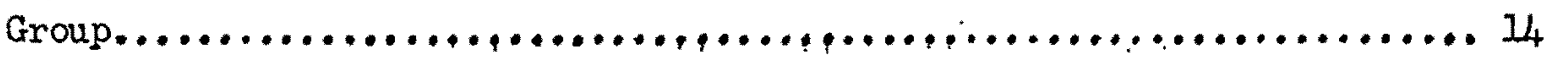

8. Means, Standard Deviations (SD) and Ranges for Male (M), Male Crossvalidation (C) and Female (F) Validation Samples of Normal, Neurotic,

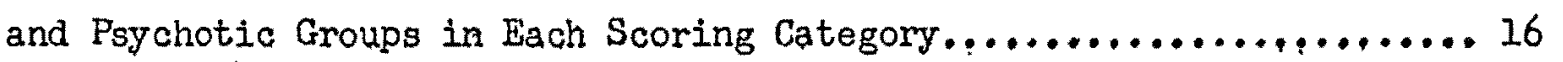

9. Summary of Median Test Results on PO, PR, PP Scores of Male Validation

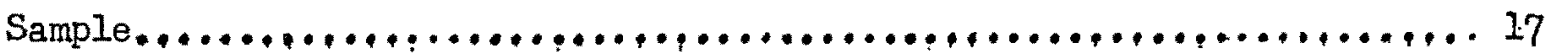

10. Summary of Median Test Results on PO, PR, PP Scores of Female Validation Sample............................................. 18

11. Sumnary of Median Test Results on FO, FR, PP Scores of Male Cross validation Sample

12. Normal-neurotic and Neurotic-psychotic Medians for Male Validation, Male Cross-validation (C), Female Validation, Total Male and Total Male and Female Samples for TAT Scoring Categories PO, PR, PP....... 20 


\section{List of Tables (cont.)}

13. Percentage of $\mathrm{Ss}$ in Fach Group Receiving Scores of $0,1,2$ on Fach

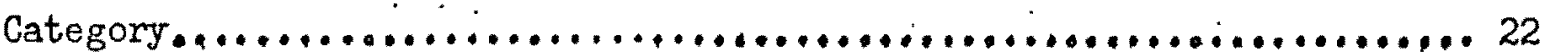

14. Product-moment Correlations between Categories PO, PR, PP and Length for Two Samples, Male and Female, Each of Three Groups, $50 \mathrm{Ss}$ in each Group......................................................... 23

15. Product-moment Correlations between PO, PR, PP and Intelligence Test Scores for Three Female Groups................................... 25

16. T-Scores for Categories PO, PR, PP........................... 27

17. T-Score Percentages of Normal, Neurotic and Psychotic Ss for Each Scoring Category,............................................, 28

18. T-Score Percentages of Normal, Neurotic and Psychotic Ss for Scoring Categories PO and PR Combined $\ldots \ldots \ldots \ldots \ldots \ldots \ldots \ldots \ldots \ldots \ldots \ldots \ldots \ldots, 29$

19. T-Score Percentages of Normal, Neurotic and Psychotic Ss for Scoring Categories PO and PP Combined..,..............................29

20. T-Score Percentages of Normal, Neurotic and Psychotic $\underline{\text { S}}$ for Scoring Categories PR and PP Combined...............................29

21. T-Score Percentages of Normal, Neurotic and Psyohotic Ss for Scoring Categories PO, FR, PP Combined...............................29 


\section{Preface}

This manual presents a concise but abbreviated statement of one objective TAT scoring system and its predictive efficiency. It is designed to facilitate application of this approach to TAT scoring. Although the rationale upon which this metiod is predicated derives from certain specific assumptions regarding personality, the clinical use of these categories does not demand any particular theoretical persuasion. The author recognizes two kinds of validity germane to projective instmments: (a) validity, prediction of clinkcal diagnosis; (b) validity 2 , prediction of personality characteristics. This manual deals only with validity ${ }_{1}$ As the material contiained herein is still largely in tentative form, the author will welcome suggestions, anmendations, elaborations, criticism. This manual owes its existence to many individuals who helped collect the data, score the protocols, apply statistical techniques, and type the various manuscripts, Their combined efforts have made this manual possible. 
Introduction

Clinical use of the TAT has been largely restricted to content analysis by the plethora of cumbersome scoring systems currently available. That scoring systems should be simple, objective, employ stimulus properties of . the TAT cards, and be related to personality theory, is becoming empirically evident. That TAT scoring can be a clerical procedure and interpretation a clinical skill is con jruent with the new look in projertive testing. The use of objective sooring does not imply abandonment of content analysis but is merely a formal aid to this process.

\section{Rationale}

Discussion of the approach to personality theory which antedated the rationale for $\mathrm{mT}$ scoring is not appropriate here (3): However, there are at least three aspects of test behavior to be considered in devising objective scoring systems (6): (a) approach to the situation (reflected, for example, in the manner standard test directions are followed); (b) normality of responses (abstractions of structural and content material included by specified percentages of "normal" Ss); (c) rarity of responses (those infrequent responses in a "normal" population which appear with significantly higher frequency in psychopathological conditions).

\section{Scoring Categories}

These three aspects of test behavior have been objectified as Perceptual Organization, Perceptual Range, and Perceptual Personalization, respectively. 1. Perceptual Organization (PO)

Description

This category reflects the S!s ability to follow the standard directions to "tell a story." Seven possible components are included: (a) card des- 
cription; (b) present behavior; (c) past events; (d) future events; (e)

feeling; (f) thought; (g) outcome.

PO $\underline{\text { Scoring Directions }}$

You are scoring to see how closely the subject followed the original test directions. Score sheets are provided (Appendix A) which are used to record PO, PR and PP. The score sheet contains a list of the seven components (abbreviated as $\mathrm{CD}, \mathrm{PB}, \mathrm{PQ}, \mathrm{FE}, \mathrm{F}, \mathrm{T}, \mathrm{O}$ respectively) and spaces to record presenoe or absence of each component for each card used. Columns have been labeled for cards 2, 3, 4, 6, 7 and space is left for any other cards which may have been administered. Each Fo component present in stwry is scored by placing a plus $(+)$ in the appropriate space on the score sheet. A minus ( - ) is scored for components not included. No score is given for frequency of appearance on each card.

Any of these cornponents which appear after the first question by the examiner (additional scores) should be entered on the sheet and the entry circled.

All stories given by the subject may be scored. The total PO score is the sum of scores to the five stories.from cards $2,3,4,6,7$. Note that space is also provided for tal]-girg frequency ( $f$ ) of components for all cards. Circled PO componenis should not be added in obtaining the total PO score. Enter total score in tor jeberd $T$; enter total additional scores in box labeled $\mathrm{T}$ add.

\section{a. Card Description (CD)}

Physical description of two or more things or persons actually present in the picture. It may be a listing such as, "This is a man, a woran, a tree, etc." It may serve to introduce the story, "The boy is on the floor".... "The woman who is by the tree is....ii In these cases there is never any action; merely description. If the word "picture" is used, then only one person or thing need follow, "This is a picture of a boy.". CD may occur anywhere in the story.

b. Present Behavior (PB)

Any activity or behavior that occurs in the present or is in the process of occurring within the picture. For example (card 2), "The man is plowing the field." ictivity which occurs outside of the frame-of-reference of the picture is scored Past Events or Future Events.

c. Past Events ( $\mathrm{PE}$ )

Things, events, situations which have taken place in the past, i.e., before the time of the scene pictured on the card and described in the story. These may be in the immediate or the remote past and must be specified and definite things, events, or situations, 
d. Future Events (FE)

Things, events, situations which will take place or do take place in the future, i.e., after the tine of the scene pictured on the card and described in the story. These may be in the immediate or remote future and must be specifio and definite things, events, or situations.

\section{ê. Feeling (F)}

Any expression of feeling or enotion on the part of the characters present in the story. This includes affect, i.e., sad, mad, in love, and desire, i.e., wishing and wanting (but not need).

\section{f. Thought (T)}

Any expression of thought, memory, dream or allied mental state present in the story. This includes decision, belief, realization, knowing, praying, figuring, etc.

\section{g. Outcome (0)}

The inclusion of a specific statement wich indicates the ending, denouement, fina?e, or conclusion of the story. This may consist in behavior, feeling, thought or even, rarely, be present by inplication in future events. If this does occur, both outcome and future events are scored. Usually appears at or near the end of the story, i,e, the last sentence or phrase.

$$
\text { 2. Perceptual Range (PR) }
$$

\section{Description}

Empirical evidence has been used to establish criteria as to content a group of "normal" Ss will include in their TAT stories a given pewcentage . of the time (11). Three separate stimulus properties were chosen for each card on the basis of inclusion by approximately 90 per cent or more of this "normal" group.

PR Scoring Directions

You are scoring to see how closely the subject adheres to norms for various aspects of the stories. The 15 stimulus properties for males are: Card 2 (a) family: young girl, woman, activity specified; adult male; (b) fields or farm; (c) books or school; Card 3 (d) figure, sex and age specified; (e) emotions noted; (f) activity specified; Card 4 (g) male: emotions noted, activity specified; (h) woman; activity speoified; (l) conflict or cooperation; Card $6(j)$ man; emotions noted, activity specified; (k) woman; emotions noted; (1) personality reforrent; Card 7 (m) older male, activity speoified; relationship specified; ( $n$ ) male, emotions noted; (o) personaltty referrent. The I5 stimulus properties for women are: 
Card 2 (a) family: young girl, activity specified; woman; adult male; (b) fields or farm; (c) books or school; Card 3 (d) female; (e) emotions noted; activity specified; (f) story: death, murder, illness, frustration; Card 4 (3) male; enotions noted; activity specified; (n) woman; activity specified; (i) conflict or cooperation; Card $6(j)$ male, activity indicated; ( $k$ ) female, emotions noted; (1) relationship indicated; Card 7 (m) adult female, activity specified, emotions noted; (n) child, female, emotions noted; (o) relationship specified. You have been provided with criteria lists on a score sheet ( $M$ or F). (Appendix A). AIl items included in each criterion must be mentioned for score to be earned. No score is given for indefinite or ambiguous statements. For example, in Card 2 (male), if the "family," the "young girl," the "woman," and the "adult male" are mentioned, no score is given because the "activity" of the "woman" is not specified.

Raad each story once, then go back and look for eaoh particular_item in each criterion; finally, check off complete criteria on the score sheet, plus $(+)$ for those present; minus $(-)$ for those not included in story.

To obtain the total PR score, add the plus scores obtained for each story, and enter in box labeled $T$.

\section{Perceptual Personalization (PP)}

\section{Description}

Some expression, words, and phrases used in the story are incongruous. and have no obvious reference to the story that $\underline{S}$ is trying to relate. These inclusions are clearly neither stimulus reproductions nor additions to the stimulus. PP are deviations from the relatively consistent, organized, cor herent protocol-product, the Tit story. These deviations, in order to be scored, must be extreme. They may refer to things labeled performance adequacy, comments, parenthetical remarks, qualifications, picture criticisms, adventitious diescriptions, vagueness, evasion, or direct personal reference. PP Scoring Directions

As you read each story you will note that certain words and phrases do not seem to belong with the rest of the story. They do not add anything to the. ideas and events in the story. These words and phrases include all questions and remarks concerning the way the subject feels about his performance, the picture, and hinself. They may refer to things which have been called "adequacy of performance," "qualification," "picture criticisms," "vagueness and evasion," and "personal reference."

Examples of these "out of place" words and phrases follow: 
Questions: "Is that a boy or a girl?" "What's that supposed to be?"

Adequacy of performance: "I can't figure that one out."

Qualifications: "wait a minute...." "It's not realiy that at a.1."

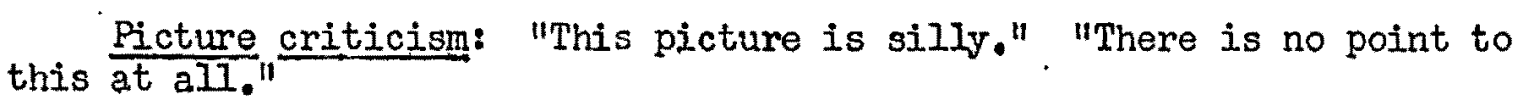

Parenthetical comments: "That's about all on that." "There is not much connected with it."

Adventitious descriptive comments: Any remarks just thrown in without apparent connection to the rest of the story. These remarks often pertain to physical description of the picture, or the people in it.

Vagueness and evasion: "or....or;" "either.... or," "more or less," "or something," "......... whatever it is."

Personal reference: Any reference to "I". Any inclusion of personal information which is identified as such by the subject.

List the words and phrases by number for each card scored on the appropriate score sheet (M or $\mathrm{F}$ ).

Iist each word or phrage to be scored separately

One point is given for each word or phrase listed.

The PP score is the total number of points for all cards scored. Enter the total PP score in the box labeled.T.

\section{Card Selection}

Five TAT cards were selected to ompose the basic life situations: Cards 2, 3BM, 4, 6BM, and 7BM for males; cards 2, 3GF, 4, 6GF, and 7GF for females. The use of short-form TAT sets has been experimentally evaluated by comparing PO scores for short-form sets with the total set of cards (7). The inclusion of particular cards was found to be of less iriportance than the actual number of cards selected. $\mathrm{IAT}$ sets of as $\mathrm{few}$ as five cards, when scored for PO, provide data which is roughly equivalent to that from the entire series. PO scores from the short-form set. for women correlated. 91 with scores from the entire set.

Table 1 presents correlations of PO scores for each card with the scores 
Table 1

Product-moment Correlations of PO Scores for

Each Card with PO Score for Al1 Cârds.

(67 Normal Female Ss)

\begin{tabular}{|c|c|c|}
\hline Card & $\underline{\underline{r}}$ & \\
\hline 1 & .72 & \\
\hline 2 & .68 & 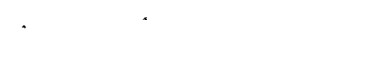 \\
\hline 3 & .76 & \\
\hline 4 & .69 & . \\
\hline 5 & .73 & \\
\hline 6 & .64 & \\
\hline 7 & .74 & \\
\hline 8 & .74 & \\
\hline 9 & .75 & - \\
\hline 10 & .77 & \\
\hline 11 & .70 & \\
\hline 12 & .70 & \\
\hline 13 & .72 & \\
\hline 14 & .78 & \\
\hline 15 & .71 & \\
\hline 16 & .60 & \\
\hline 17 & .63 & \\
\hline 18 & .63 & \\
\hline 19 & .65 & \\
\hline 20 & .64 & $\cdot$ \\
\hline Mean $r$ & .70 & (z transformation) \\
\hline
\end{tabular}


for the entire set with $Z$ transformations to provide a mean correlation.

Table 2 presents the product-moment intercorrelations of PO scores for normal female Ss. These data indicate that the stinulus-values of the selected TAT cards (in terms of $N$ of $P O$ items) are approximately equivalent.

Table 3 summarizes the product-moment intercorrelations of scoring categories PO, PR, PP, for three diagnostic groups in the male sample (2). Significant relationships obtain between all three categories. PO and PP are inversely related such that high scores on PO tend to occur with low scores on PP. To a considerably lesser degree PR and PP are also inversely related. These figures raise the question of overlap between $P O$ and $P R$ especially, and to a lesser extent between PO and PP. Further research must explore the significance of these interrelationships. The assumptions, concerning personality which led to this TAT manual are thoroughly congruent with such associations among scoring categories,

\section{Subjeets}

The Ss on whom this manual is based were from validation and crossvalidation samples $(4,8,9,10)$. The validation sample contained $300 \mathrm{Ss}, 150$ males and 150 females, with 100 normals, 100 neurotics, 100 psychotics. The cross-validation sample contained 90 male Ss, 30 normals, 30 neurotics, 30 psychotics. The normal male Ss were college students with no history of psychiatric illness; the normal female Ss were student nurses with IMPI T scores all below 70. The neurotic and psychotic male Ss were chosen in terms of previously determined criteria: (a) hospitalized; (b) diagnostic agreement between psychiatrist and psychologist; (c) independent diagnostic formulations; (d) diagnosis: neurosis or schizophrenia. The neurotic and psychotic female Ss were chosen in terns of these same criteria with one exception; out patient clinic neurotics were used. The males in the cross-validation sample were 
Table 2

Product-moment Intercorrelations

Between PO Scores on Five Cards

(67 Normal Female ss)

$\begin{array}{ccccc}\text { Card } & 3 & 4 & 6 & 7 \\ 2 & .62 & .40 & . .50 & .53 \\ 3 & & .61 & .57 & .58 \\ 4 & & & .58 & .57 \\ 6 & & & & .60\end{array}$

Note.--A1I figures are significant at $\$ 01$ level of confidence. 
Table 3

Product-moment Intercorrelations of

Categories PO, PR, PP for Three

Groups in the Male Sample

Category PR PP

PO

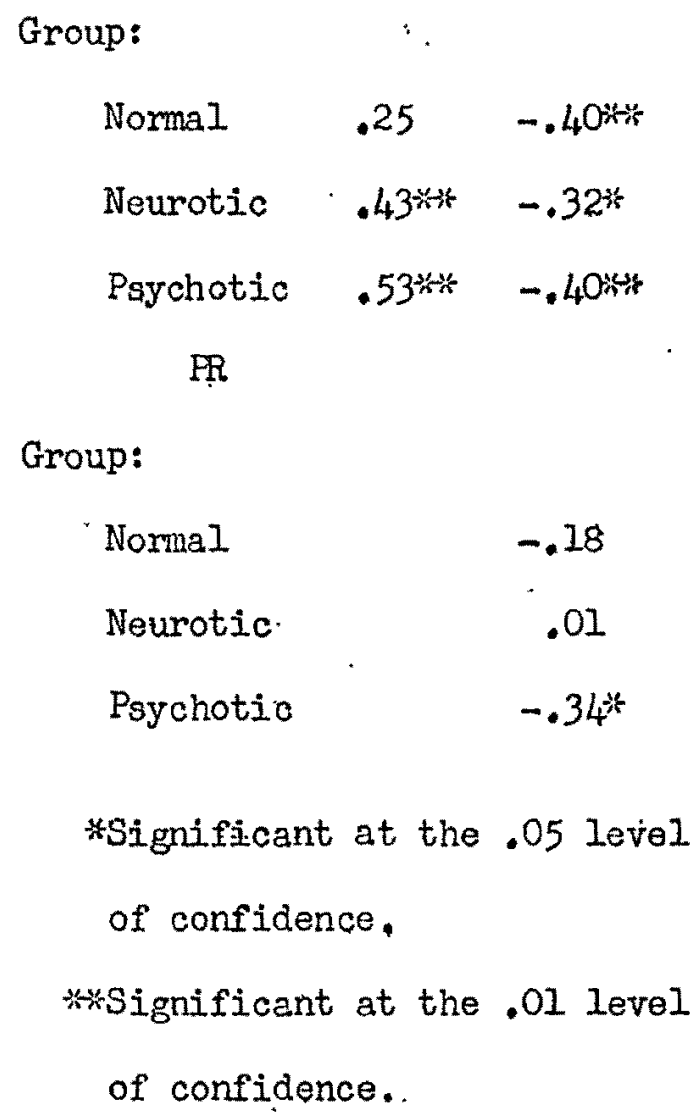


chosen in terms of these same criteria with one exception; outpatient clinic neurotics were used. $A I I S$ s were between the ages of 20 and 40 , with I.Q. scores of average or better.

\section{Reliability}

Two kinds of scorer reliability were used $(5,6)$ : (a) scoring category reliability; (b) reliability of the items composing the categories. Scorer reliability was determined by means of percent of agreement. Both kinds of scorer reliability were calculated for all three groups, with various scorers, psychologists and clerks. From the male validation sample 75 stories, 25. from each sroup, were randomly drawn, coded, and scored for reliability. The same process were used for 150 stories from the female sample and 75 stiories

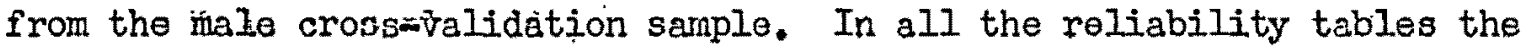
figures reported for the male validation sample represent the average per cent of agrement for three scorers; the figures for the male cross-validation sample and the female sample represent the percent of agreement for two scorers.

Table 4 summarizes the per cent of agreement figures for scoring category reliability. The highest figures obtained for the male valldation sample are reported. The reliability for $P O$ ranges from 88 to. 94 per cent of agreement; PR from 86 to 91 per cent; and PP from 75 to 86 per cent. The increase in reliability for the female and male cross-validation samples is attributable to: (a) additional practice in scoring; (b) formalization of scoring criteria on an easily used score sheet. It should be noted that although the PR criteria differ for male and female Ss that the reliability of scoring is almost identical.

The reliability of scoring separate $\mathrm{PO}$ and $\mathrm{FR}$ items is presented in Tables 5 and 6. The mean reliability figures (scoring category reliability) differ in 


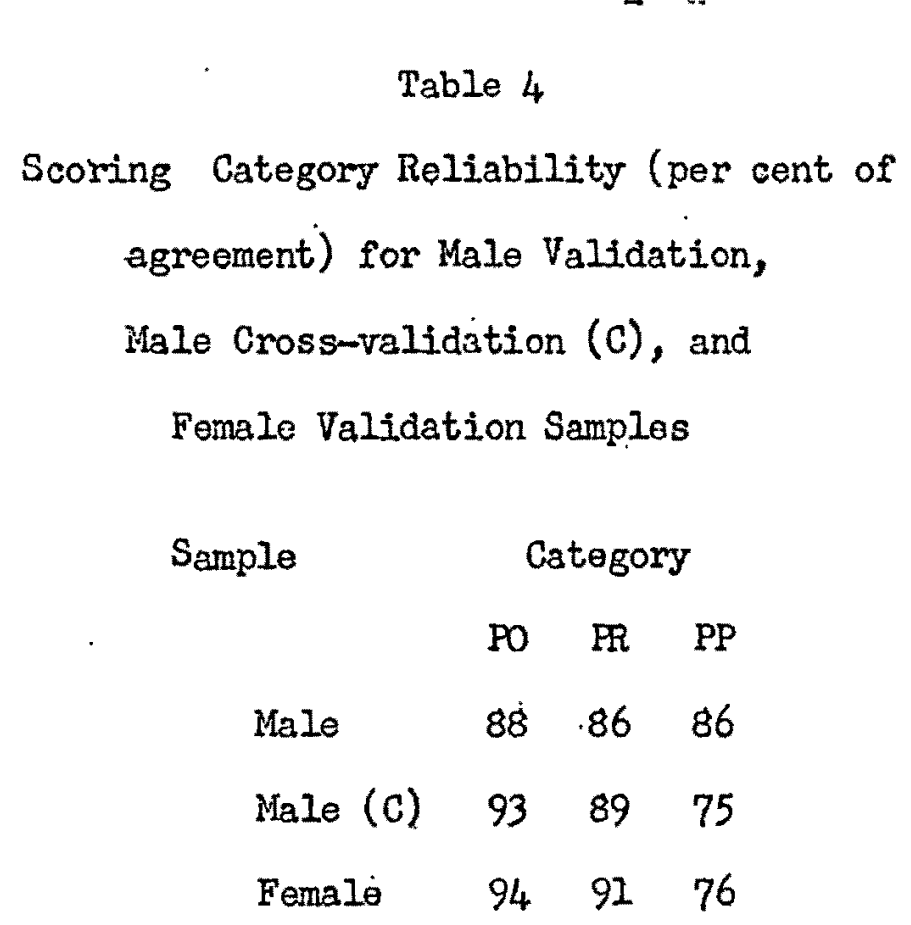

$-11-$

Table 4

Scoring Category Reliability (per cent of agreement) for Male Validation, Male Cross-validation (c), and Female Validation Samples

\begin{tabular}{llll} 
Sample & \multicolumn{3}{c}{ Category } \\
& PO & FR & PP \\
Male & 88 & .86 & 86 \\
Male (C) & 93 & 89 & 75 \\
Female & 94 & 91 & 76
\end{tabular}


Table 5

PO Item Reliability (per cent of agreement)

for Male Validation, Male Cross-validation

(c), and Female Validation Samples

Item Sample

$\begin{array}{lccc} & \text { Male } & \text { Male (C) } & \text { Female } \\ \text { Card Description } & 91 & 91 & 91 \\ \text { Present Behavior } & 89 & 91 & 94 \\ \text { Past Events } & 90 & 91 & 94 \\ \text { Future Events } & 89 & 97 & 93 \\ \text { Feoling } & 89 & 90 & 95 \\ \text { Thought } & 81 & 89 & 96 \\ \text { Outcome } & 92 & 99 & 96 \\ & & & \\ \text { Mean } & 89 & 93 & 94\end{array}$


Table 6

PR Item Reliability (per cent of agreement)

for Male Validation, Male Cross-validation

(c), and Female Validation Samples

Item

$\because$ Male Male (c) Female

1

69

93

93

100

100

87

87

87

87

80

93

80

87

80

87

93

$\begin{array}{llll}\text { Mean } & 80 & 89 & 91\end{array}$

87

100

87

100

93

83

93

93

90

93.

87

$\begin{array}{llll}12 & 62 & 87 & 87\end{array}$

$\begin{array}{llll}13 & 84 & 80 & 80\end{array}$

$\begin{array}{llll}3.4 & 69 & 87 & 97\end{array}$

$\begin{array}{llll}15 & 69 & 93 & 100\end{array}$


Table 7

PP Category Reliability (per cent of agreement)

by Sexés and Diagnơstic Group

Bek dfoup

Nomal Nolurotic Psychotic

Male

88

84

76

Male (c)

82

73

74

Femalo

78

77

76 
some instances for the male sample from those reported in Table 4 because the component entries are themsel.ves mean agreements of three scorers. No consistent or large differences appear between males or females and there were no significant differences in scoring the three diagnostic groups. Thus, the reliability figures for each diagnostic group are omitted. The rellability of scoring separate PO items (on all samples) ranged from 89 to 97 per cent of agreement; PR from 60 to 100 per cent of agreement.

Table 7 presents the reliability of scoring PP for males, females, and diagnostic groups. The lowered PP figures reflect ambiguity in the scoring directions, i.e., the absence of specified criteria to look for in the stories. PP reliability figures are reported by diagnostic group because ambigulty increases with bizarreness present in the TAT story. The selection of just what to score becomes difficult as little in the protocol relates to the continuity of the story.

\section{VaIidity}

Table 8 presents the means, ranges and standard deviations for each category from all diagnostic groups on all samples. Validity was estimated by a nonparametric, median, chi-square analysis (Tables $9,10,11$ ). The statistical fact of significant differences between diagnostic groups does not indicate the predictive efficiency of a scoring system. For this reason prediction scores were developed by using as criteria (cut-off scores) the normalneurotic and neurotic-psychotic medians for each sample (Table 12). The relatively emall differences between male and femalo samples permit use of combined medians obtained from the total sample rather than separate cut-off scores for each sex. These combined medians (rounded for convenient clinical application) are 23 and 15 for PO; 11 and 7 for PR; 2 and 6 for PP. $P O$ and PR scores above the normal-neurotic medians were given 0; scores between the 
Table 8

Means, Standard Deviations(SD) and Ranges for Male (M), liale Cross-validation (C) and Female (F) Validation Samples of Normal, Neurotic, and Psychotic Groups on Each Scoring Category

Çategory

Mean

$S D$

Range

$\begin{array}{llllllllll}M & C & F & M & C & F & M & C & F\end{array}$

$\mathrm{PO}$

Group:

$\begin{array}{llllllllll}\text { Normal } & 26.6 & 26.5 & 27.5 & 3.7 & 2.6 & 3.9 & 19-32 & 22-31 & 16-35\end{array}$

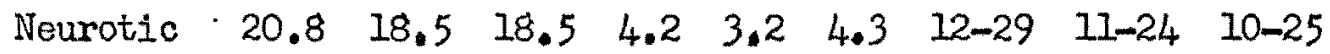

$\begin{array}{llllllllll}\text { Psychotic } & 13.2 & 10.8 & 8.5 & 4.1 & 2.9 & 2.9 & 6-24 & 6-21 & 5-18\end{array}$

PR

Group:

$\begin{array}{llllllllll}\text { Normal } & 12.1 & 13.4 & 14.2 & 1.8 & 1.3 & 1.0 & 8-15 & 11-15 & 11-15\end{array}$

$\begin{array}{llllllllll}\text { Neurotic. } & 9.8 & 8.8 & 9.7 & 2.2 & 1.5 & 1.7 & 4-15 & 5-11 & .5-12\end{array}$

$\begin{array}{llllllllll}\text { Psychotic } & 4.9 & 5.2 & 5.4 & 5.8 & 1.6 & 1.9 & 0-12 & 1-9 & 1-11\end{array}$ PP

Group:

$\begin{array}{lllllllllll}\text { Normal } & 1.0 & .3 & .2 & .5 & 1.3 & 1.1 & 0.6 & 0-6 & 0-13\end{array}$

$\begin{array}{llllllllll}\text { Neurotic } & 5.9 & 3.8 & 6.1 & 2.7 & 4.3 & 6.0 & 0-17 & 0-29 & 0-30\end{array}$

$\begin{array}{llllllllll}\text { Psychotic } & 12.1 & 5.0 & 8.5 & 9.1 & 6.0 & 6.6 & 1-43 & 0-40 & 0-29\end{array}$ 


\section{Table 9}

Summary of Median Test Results on PO, PR, PP Scores of hale Validation Samplo

Combined Above

Category iledian hiedian $x^{2} p$

$\mathrm{PO}$

Group:

$\begin{array}{lrrrr}\text { Normal } & & 37.0 & & \\ \text { Neurotic } & 24.50 & 13.0 & 23.0 & 4.001 \\ \text { Normali } & & 46.5 & & \\ \text { Pyychotic } & 20.25 & 3.5 & 73.9 & 4.001 \\ \text { Neurotic } & & & \\ \text { Psychotic } & 16.94 & 40.8 & & \\ & & 9.2 & 39.9 & 4.001\end{array}$

PR

Group:

Normal

Neurotic

11.19

35.5

14.5

$17.6<.001$

Nंormal

Psychotic

8.90

46.8

3,2

$76.0 \quad 5.001$

Neurotic

Psychotic

7.68

42.7

7.3

$50.1 \quad .001$

PP

Group:

$\begin{array}{lrrrc}\text { Normal } & & 12.6 & & \\ \text { Neurotic } & 1.90 & 37.4 & 24.6 & 4001 \\ \text { Normal } & & 7.7 & & \\ \text { Psychotic } & 2.83 & 42.3 & 47.9 & 4001 \\ \text { Neurotic } & & 17.9 & & \\ \text { Psychotic } & 7.37 & 32.1 & 8.1 & 5.01\end{array}$


Table 10

Summary of Median Test Results on PO, PR,

PP Scores of Female Validation Sample

Combined Above

Category Median Median $x^{2} \quad p$

PO

Group:

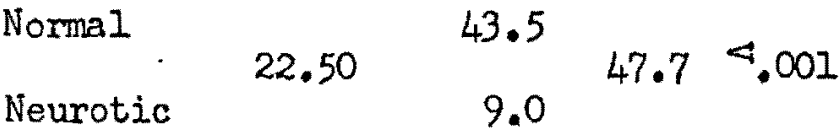

Normal

Psychotic

16.50

49.5

$94.1<.001$

Neurotic

$12.10 \quad 44.7 \quad 59.3<.001$

Psychotic

6.2

PR

Group:

$\begin{array}{lrrrr}\text { Normal } & 11.90 & 48.2 & & \\ \text { Neurotic } & & 14.1 & 49.5 & .001 \\ \text { Normal } & 10.84 & 50.0 & & \\ \text { Psychotic } & & 1.0 & 96.1 & 4.001 \\ \text { Neurotic } & & 44.3 & & \\ \text { Psychotic } & 7.68 & 15.8 & 39.9 & 4.001 \\ \quad & & 1 . & & \end{array}$

Group:

$\begin{array}{lrrrr}\text { Normal } & 1.50 & 6.5 & 62.6 & 4.001 \\ \text { Neurotic } & . & 46.0 & \\ \text { Normal } & & 7.1 & & \\ \text { Psychotic } & 1.30 & 45.4 & & \\ \text { Neurotic } & & 23.8 & & \\ \text { Psychotic } & 6.84 & 29.5 & 1.3\end{array}$


Table 11

Summary of Median Test Results on PO, PR, PP

Scores of Male Cross-validation Sample

Combined Above

Category Median Median $\mathrm{X}^{2} \quad \mathrm{p}$

PO

Group:

Normal

$\begin{array}{lrrrr}\text { Normal } & 23.00 & 29.0 & & \\ \text { Neurotic } & & 1.0 & & \end{array}$

29.0

Normal

Psychotic

21.50

30.0

$58.0<.001$

Neurotic

14.00

FR

Group:

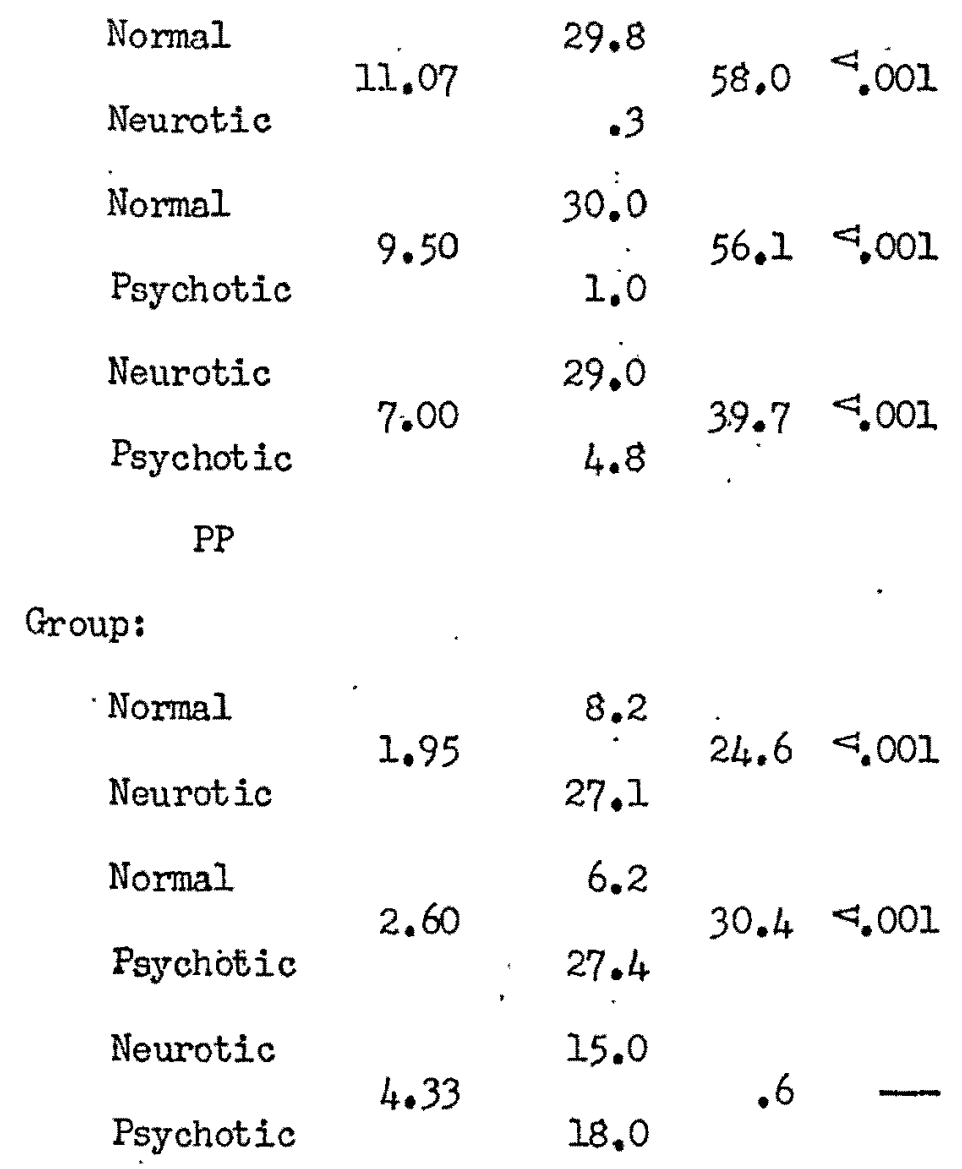


Table 12

Normal-neurotic and Neurotic-psychotic Medians for Male Validation, Male Cross-Validation (c), Female Validation, Total Male, and Total Male and Female Samples for TAT Scoring Categories PO, PR, PP

Category

Median

Iormal-neurotic Neurotic-p̄sychotic

PO

Sample:

Male

24.5

16.9

Male (C)

23.0

14.0

Feinalo

22.5

12.1

Total Male

23.8

16.3

Total M \& F

23.4

14.7

PR

Sample:

Male

11.2

7.7

Male (C)

11. I

7.0

Feñale.

11.9

7.7

Total Malo

11.1

7.3

Total M \& F

11.4

7.5

PP

Sample:

Male

1.9

7.4

Male (c)

1.9

4.3

Feñale

1.5

6.8

Total Male

1.9

6.2

Total M \& F

1.8

6.4 
normal-neurotic and neurotic-psychotic medians were given 1; and scores below. the neurotic-psychotic medians were given 2. PP scores below the normalneurotic median were given 0 ; scores between the normal-neurotic median and the neurotic-psychotic median were given 1; and scores above the neuroticpsychotic median were given 2. Table 13 presents the percentages of Ss male. (validation plus cross-validation samples) and female, in each diagnostic group receiving scores of $0,1,2$. This table can be used directly to evaluate the pnobability that a particular scored TAT record (when translated into prediction scores) will fall into the normal, neurotic, or psychotic group. This table constitutes preliminary norms for these three TAT scoring categories.

Past TAT research (1) has indicated that length (number of words) may be related to objective sporing. The question of whether the median test differences were a result of length was raised in the male validation study. That is, would the groups have been alike in PO scores had their protocols been of equivalent length? The assumptions necessary for covarience adjustments are not satisfied and a crude test which provides a correction for regression and takes trend into account was used. A graphical procedure was employed analogous to the riedian test except that a kind of average regression line or "sliding dividing line" was used in lieu of the median, Regression lines were plotted for the three groups for $\mathrm{PO}$ on length, a line of split (sliding dividing line) was made for each pair of groups, the number of cases above and below were counted, and chi-square applied. No appreciable differences in PO were found. $A$ less rigorous method would be to plot PO against length for the total sample, draw a line fitting the medians of the columrs and compare by chi-square the proportion of the cases in each group falling above the line of medians.

Product-moment correlations were calculated between scoring categories and length for the male and female samples (Table 14 ). The magnitude of the PO- 
Table 13

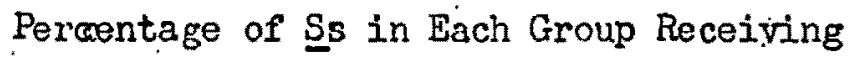

Scores of 0, 1, 2 on Each Category

Group .

$$
\text { Category }
$$

PO PR PP

NormaI

Score:

$\begin{array}{rrrr}0 & 82 & 84 & 87 \\ 1 & 18 & 16 & 12 \\ 2 & 0 & 0 & 1\end{array}$

Neurotic

Score:

$\begin{array}{llll}0 & 17 & 14 & 26 \\ 1 & 68 & 81 & 40 \\ 2 & 15 & 5 & 34\end{array}$

Psychotic

Score:

0

112

1

$\begin{array}{lll}16 & 29 & 42\end{array}$

2

$83 \quad 70 \quad 45$ 
Table 14

Product-moment Correlations between Categories PO, PR,

PP, and Length: for:Two \$amples; Male and Female, Each of Three Groups, 50 Ss in Each Group

Length

Category

PO $\quad$ R $\quad$ PP

iale

Group:

$\begin{array}{llll}\text { Normal } & .23 & .15 & .16 \\ \text { Neurotic } & .52 * \% & .12 & .11 \\ \text { Psychotic } & .30 * & -.02 & .21 \\ \text { Female } & & & \end{array}$

Group:

$$
\begin{array}{llll}
\text { Normal } & .55 * * & .10 & -.00 \\
\text { Neurotic } & .34 * & .50 * * & .40 \% \\
\text { Psychotic } & .42 * * & .20 & .39 \% * \\
\text { *Significant at the } & .05 \text { level of } \\
\text { confidence. } \\
\text { * } \\
\text { confignificant at the } .01 \text { level of } \\
\text { confidence. }
\end{array}
$$


length correlations for the male and female samples do not.differ to any great extent. The marked similarity of the respective distributions indicates that the influence of length on median test differences for the female sample is not important. Some PR-length and PP-length correlations are significant for the female sample. However, neither correlation for the normal group approaches significance. This suggests that length does not influence the scoring categories per se but may be related to psychopathology. Again the magnitude of the obtained correlations. In comparison with the magnitude of the chi-square differences between groups provides evidence against any appreciable constant effect on either PR or PP prediction scóres.

Although consensus of experts has not considered intelligence to be related to TAT scores, product-moment correlations were calculated between scoring categories and intelligence as estimated by Wechsler-Bellevue, Form I, I.O. scores (Table 15). The correlations botween PO and PR scores and intelligence scores for neurotics were significant at 4.05 . and $\$ .05$ levels of confidence respectively. None of the correlations for the normal or psychotic groups were significant. It is suggested that I.Q. scores and these TAT scoring categories are not related per se but that those neurotics with higher Intelligence tend to be more in contact and thus obtain better TAT scores.

\section{T Scores}

Several problems are involved in use of Table 13 as preliminary norms for these TAT scoring categories. The complexity of the clerical process, the absence of uniform procedure, and the use of unequal score units makes mandatory a more communicable method of presenting normative data. For these reasons conversion to T-sceore equivalents was undertaken.

T-scores assume a standard group of $\underline{S} s$. Although the total number of $\underline{S}$ remains relatively small (N-390) and may not be representative of "normal" or. 
Table 15

Product-moment forrelations between

$\mathrm{PO}, \mathrm{PR}, \mathrm{PP}$ and Intelligence Test

Scores for Three Female Groups

Intelligence Category

FO PR PP

Group:

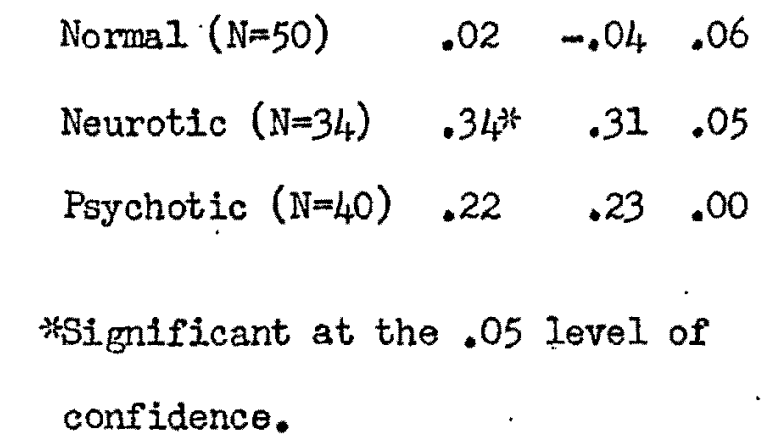


clinical populations over a broad range of situations, the advantages of Tscores are recognized. Primarily, however, the opportunity for maximizing differences between groups by use of combined scores was obtained. Thus, these scores when normalized becone units common to psychological measurement and their meaning is enhanced.

Table 16 presents the T-score equivalents for each TAT scoring category. Table 17 contains T-score percentages of normal, neurotic, and psychotic samples for each scoring category. It will be noted that Tables 13 and 17 present highly similar percentage figures, differing only as a function of choice. of cut-off points. However, when T-scores are added to provide the combinations for $P O$ and $P R, P O$ and $P P, F R$ and $P P$, and $P O, P R, P P$, striking differences occur in the predictive efficiency of the scoring categories. Tables 18, 19, 20, 21 provide this informati on. When PO and PT T-scores are combined (Table 18), 79 per cent of normal Ss fall between scores of 112 and 145; 88 percent of neurotic Ss fall between 89 and 111 ; and 83 per cent of psychotic Ss fall between 49 and 88. Combinations of $\mathrm{PO}$ and $\mathrm{PP}$ ( $\mathrm{Table} 19$ ) and $\mathrm{PR}$ and $\mathrm{PH}$ ( $\mathrm{Table} 20$ ) do not provide any increments to prediction. When all three scoring categories are combined (Table 21), 88 per cent of normal Ss obtain combined T-scores of 166-to 203; 81 per cent of neurotic Ss obtain scores between 134-165; and 79 per cent of psychotic Ss obtain scores between 70 and 133.

It is suggested that scores from each category be transformed into T-score equivalents ( $T a b l e ~ 16$ ), these T-scores added, and Table 21 be used directly to evaluate the probability of accurate diagnostic plecement of a given individual S.

\section{Discussion}

This manual has presented TAT scoring categories which may be reliably scored naive scorers and which provide "correct" prediction of a signifi- 
Table 16

T Scores for Categories PO, PR, PP .

T Score
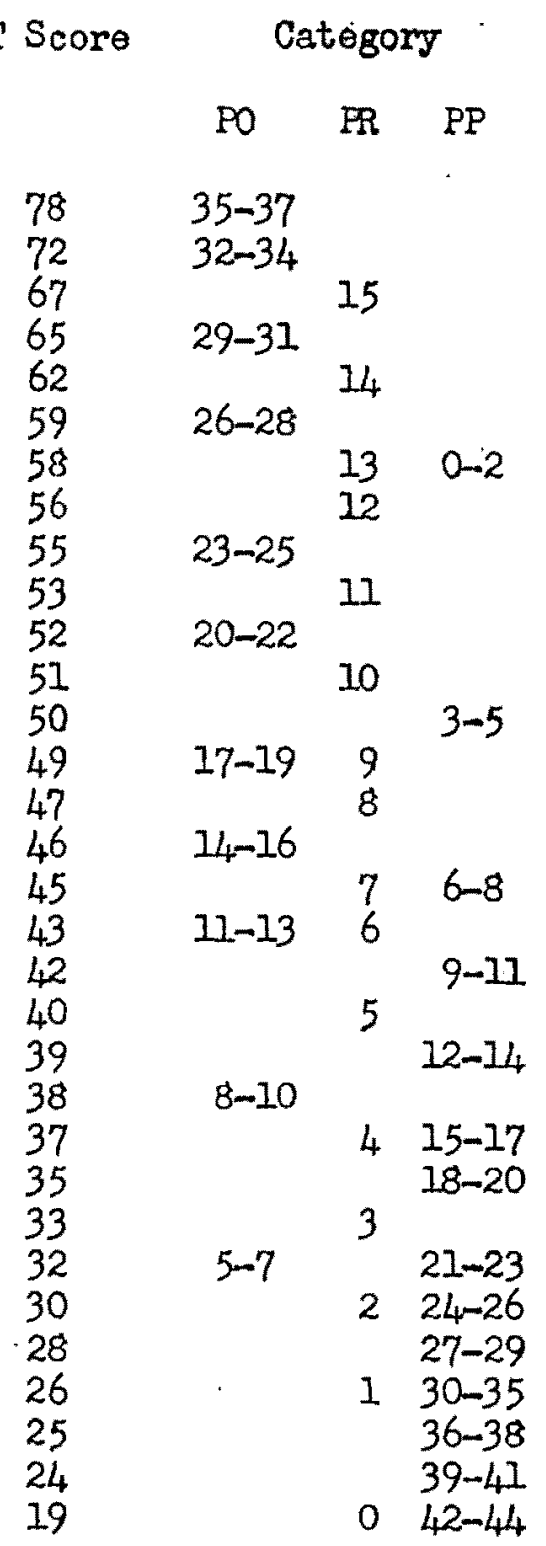
Table 17

T Score Percentages of Normal, Neturotic and

Psychotic Ss for Each Scoring Category

T Soore Normal Neurotic Psychotic

$\begin{array}{lllllllll}\text { PO } & \text { RR } & P P & \text { PO } & \text { PR } & P P & P O & P R & P P\end{array}$

$\begin{array}{llllllllll}55-78 & 88 & 84 & 87 & 24 & 14 & 25 & 2 & 1 & 13\end{array}$

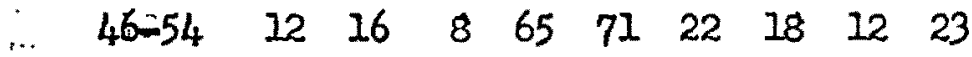

$\begin{array}{llllllllll}19-45 & 0 & 0 & 5 & 11 & 15 & 53 & 80 & 87 & 64\end{array}$ 
Table 18

T Score Percentages of Normal, Neurotic and Psychotic

Ss for Scoring Categories $\mathrm{PO}$ and $\mathrm{FR}$ Combined

T Score Normal Neurotic Psychotic

$\begin{array}{rrrr}112-145 & 79 & 6 & 0 \\ 89-111 & 21 & 88 & 17 \\ 49-88 & 0 & 6 & .83\end{array}$

Table 19

T Score Percentages of Normal, Neurotic and Psychotic

Ss for Scoring Categories PO and PP Combined

T Score Normal Neurotic Psychotic.

$\begin{array}{cccc}109-136 & 92 & 18 & 2 \\ 89-108 & 8 & 62 & 27 \\ 49-88 & 0 & 20 & 71\end{array}$

Table 20

T Score Percentages of Normal, Neurotic and Psychotic

Ss for Scoring Categories PR and PP Combined

T Score Normal Neurotic Psychotic

$\begin{array}{cccc}108-125 & 92 & 14 & 1 \\ 91-107 & 8 & 65 & 23 \\ 38-90 & 0 & 21 & 76 \\ & & \text { Table } 21 & \end{array}$

T Score Percentages of Normal, Neurotic and Psychotic

Ss for Scoring Categories PO, PR, PP Combined

: T Score Normal Neurotic Psychotic

$\begin{array}{llll}166-203 & 88 & 9 & 1\end{array}$

$\begin{array}{llll}134-165 & 12 & 81 & 20\end{array}$

$\begin{array}{llll}70-133 & 0 & 10 & 79\end{array}$ 
cant percentage of three diagnostic zroups. However, the information actually obtained by this scoring system goes considerably beyond prediction of clinical diagnosis. The scores of an $\underline{S}$ are believed to represent "degree of psychiatric illness," Thus, any expectation of 100 per cent distinction between groups would not be supported.

Miental illness; as tapped by this system, consists in deviations from nomative $\mathrm{TA}^{\mathrm{T}}$ behavior and represents changes in subjective, internalized meaning systems called "reality". Certain concomitants of mental illness are emphasized by this system: (a) awareness of reality is diminished; (b) experience can be organized with difficulty if at all; (c) the desire to give an acceptable account of oneself diminishes. These appear as attributes of a loss of psychic energy necessayy for optinal individual function. The manual can be considered an enterprise preliminary to the major responsibility of any projective technique, i.e., validity $2^{\circ}$ 


\section{References}

1. Dana, R. H. The Thematic Apperception Test applied to an experinent In perception and personality. Unpublished bachelor's thesis, Princeton Unistiv., 1949:

2. Dana, Rt $\mathrm{H}$; The diagnostic efficacy of a theoretically derived objective scoring system for the Thematic Apperception Test. Unpublished doctorits thesis, Uniti of Illinots; 1953.

3) Dana, $R_{i} \mathrm{H}$ \& Personality Orientationt an organizational focus for durrent researchi, J. Psychol., 1954, 37, 139-150;

4i Dana, Ri $\mathrm{H}$ i Cilnical diagnosis and objective TAT scóring, Ii abnormi soc: Bsychblas, 1953, 50, 19-25.

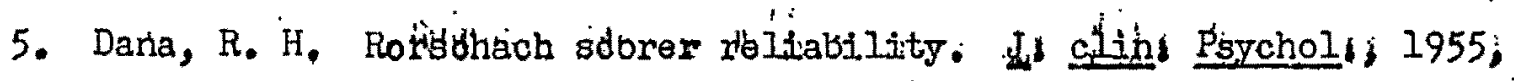
11], 401-403.

6. Dana, R. H. The objectification of projective techntques: rationald, Psychol. Rep., 1955, 1, 93-102.

7. Dana, R. H. Selection of abbreviated TAT sets. J. Glin. Psychol., in press.

8. 'Dana, R. H. Cross-validation of objective TAT scoring. I. consult. Psychol., in press.

9. Dana, R. H. An application of objective TAT scoring. I. prof. Tech., in press.

10. Dana, R. H. Norms for three aspects of TAT behavior. I. gen. PEychol. in press.

11. Fleming, Edith A descriptive analysis of responses in the Thematic A. pperception Tost. Ui:published master's thesis, Univ. of Pittsburgh, 1946. 
Appendix A

Score sheet, male
Score sheet, female 


\section{TAT Score Sheet: Male}

Perceptual Organization (PO), Perceptual Range (PR), Perceptual Personalization (PP)

Name

PO

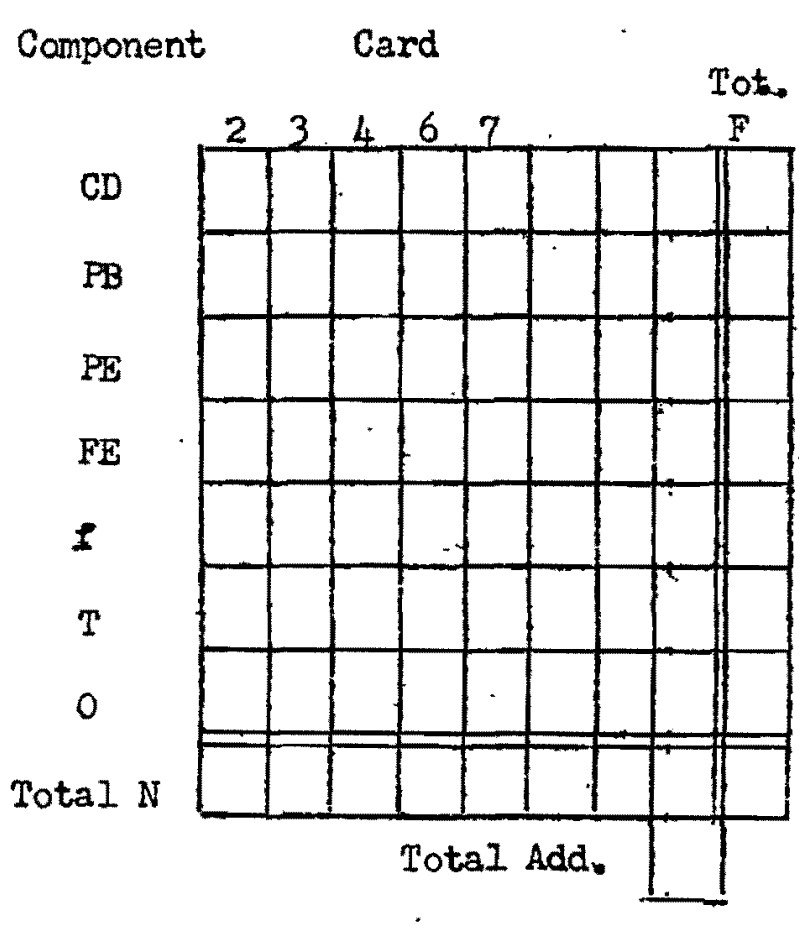

Sum $T$
Age

PR

PP

Criteria

(List by card \#)

$2 \square$ a. Family: young girl, woman, activity specified; adult male.

b. Fields or farm.

c. Books or school.

$3 \square$ d. Figure, sex and age specified.

a. Emotions noted.

f. Activity specified.

$4 \square$. ifale; enotions noted, activity specified.

h. Woman; activity specified.

i. Conflict or cooperation.

$6 \square$ j. lian; emotions noted, activity specified.

k. Woman; emotions noted.

l. Personality referrent.

$7 \square \mathrm{m}$. Older male, activity specified, relationship specified.

n. Male, emotions noted. o. Personality referrent.

$\mathrm{T}$

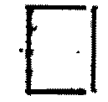

$\mathrm{T}$

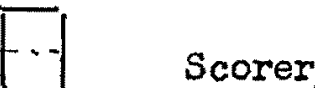


TAT Score Sheet: Female

Perceptual Organization (PO), Perceptual Range (FR), Perceptual Personalization (PP)

Name

PO
Age

FR

Criteria
PP

(Iist by card $\ddot{i r}$ )

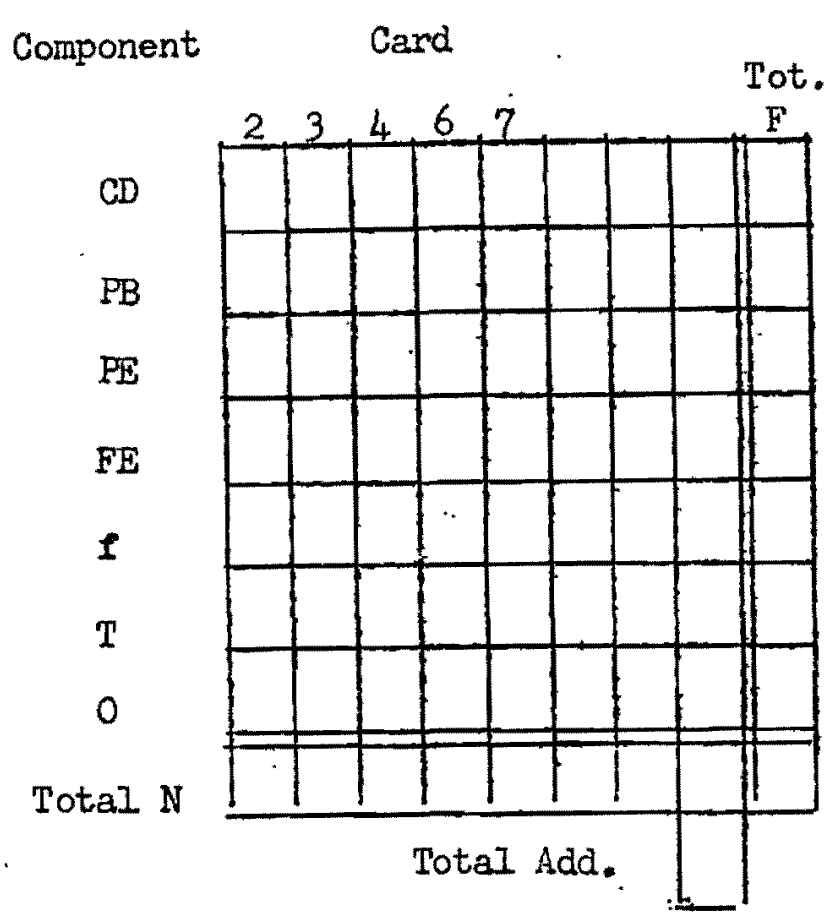

2

a. Family: young girl, activity specified; woman; adult male.

b. Fields or farm.

c. Books or school.

31 d. Female.

e. Imotions noted; activity spec.

f. Story: death, inurder, illness, frustration.

i g. Male; emotions noted; activity specified.

h. Woman; activity specified.

i. Conflict or cooperation.

$6 \square$ j. Male, activity indicated.

k. Female, enotions noted.

1. Relationship indicated.

$7 \square \mathrm{m}$. Aduit female, activity spec, emotions noted.

n. Child, fenale; enotions nated.

o. Relationship specified.

T

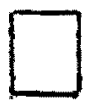

T

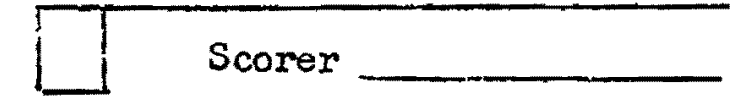

